\title{
Pendampingan Inovasi Olahan Es Krim Jahe-Kencur pada Kelompok Wanita Tani di Mangliawan Malang
}

\author{
Nour Athiroh AS dan Nurul Jadid Mubarakati \\ Fakultas MIPA, Universitas Islam Malang, Indonesia \\ nour.athiroh@unisma.ac.id
}

Received: $24^{\text {th }}$ February 2020 | Accepted: $29^{\text {th }}$ July 2020 | Publihsed: $20^{\text {th }}$ August 2020

Key word:

galangal ;

ginger;

ice cream;

innovation;

processed foods

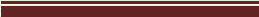

\section{Kata Kunci}

kencur; jahe; es krim ; inovasi ; olahan

\section{Abstract}

Ginger and galangal powder are less attractive to people in Mangliawan village. The cooperative's ginger powder sales business experienced a setback. The aim is to provide creativity and innovation assistance to this ginger powder as a raw material for ice cream. The phenomenon of this decade appears in various variants of ice cream, but there is no gingergalangal based ice cream business yet. The service method consists of: 1) program socialization, 2) training in making ice cream, 3) formation of nongovernmental organizations as program partners, 4) program monitoring, 5) focus group discussion, f) evaluation. Measurement of the impact of the activity was carried out using a questionnaire technique which aims to obtain a direct picture of the community in Mangliawan village. The results of the service program are 1) the public's knowledge of the potential of kencur ginger and its processing has increased; 2) Partners know how to make kencur ginger ice cream; 3) public knowledge of the benefits of ginger ice cream increases; 4) There is a desire of the respondent to open a gingerkencur ice cream business plan and increase the economic level.

\section{Abstrak}

Jahe dan bubuk lengkuas kurang diminati masyarakat di desa Mangliawan. Usaha penjualan bubuk jahe milik koperasi mengalami kemunduran. Tujuannya untuk memberikan bantuan kreativitas dan inovasi pada bubuk jahe ini sebagai bahan baku pembuatan es krim. Fenomena dekade ini muncul dalam berbagai varian es krim, namun usaha es krim berbahan dasar jahe-lengkuas belum ada. Metode pelayanan terdiri dari: 1) sosialisasi program, 2) pelatihan pembuatan es krim, 3) pembentukan lembaga swadaya masyarakat sebagai mitra program, 4) monitoring program, 5) focus group discussion, f) evaluasi. Pengukuran dampak kegiatan dilakukan dengan teknik angket yang bertujuan untuk mendapatkan gambaran langsung tentang masyarakat Desa Mangliawan. Hasil dari program pengabdian tersebut adalah 1) pengetahuan masyarakat tentang potensi jahe kencur dan pengolahannya meningkat; 2) Mitra mengetahui cara membuat es krim jahe kencur; 3) pengetahuan masyarakat tentang manfaat es krim jahe meningkat; 4) Adanya keinginan responden untuk membuka rencana usaha es krim jahe-kencur dan meningkatkan taraf ekonomi. 


\section{PENDAHULUAN}

Kesadaran masyarakat dalam mengkosumsi produk makanan atau minuman herbal sangat tinggi pada satu dekade terakhir. Hal ini dipicu dengan meningkatnya pengetahuan bahwa tanaman herbal atau tanaman obat memiliki senyawa fitokimia yang baik untuk pencegahan dan pengobatan. Selain itu, ada kecenderungan pemahaman bahwa dengan mengkonsumsi tanaman herbal semakin menjauhkan dari efek sintetis obat kimia (Winarti \& Nurdjanah, 2005).

Indonesia memiliki tanaman herbal dan rempah yang melimpah. Peluang industri makanan dan minuman herbal juga semakin meningkat dengan adanya kecenderungan masyarakat yang memilih untuk mengkonsumsi minuman atau makanan herbal yang lebih dekat dengan alam (Andriati \& Wahjudi, 2016).

Desa Mangliawan merupakan salah satu desa yang ada di Kecamatan Pakis, Kabupaten Malang. Dilihat dari kondisi geografis desa Mangliawan berada tidak jauh dari daerah perkotaan, sehingga di desa ini juga tidak terlalu memiliki lahan yang luas. Dengan keterbatasan tersebut, masyarakat di desa ini mengembangkan tanaman obat keluarga. Desa Mangliawan memiliki 4 dusun yang salah satunya yaitu dusun Krajan Barat. Di dusun Krajan Barat tepatnya di RW 15 terdapat kumpulan wanita tani yang terdiri dari 10 orang dan merintis usaha tanaman obat keluarga. Usaha ini berawal dari adanya program pemerintah yang berupa Kawasan Rumah Pangan Lestari (KRPL). Tujuan program ini untuk menghijaukan alam dengan membudidayakan tanaman yang bermanfaat.

Ibu Sisatgas Dwiko Putri (Penggagas Kelompok Wanita Tani) Memiliki ide untuk menanam Toga (Tanaman Obat Keluarga) dengan alasan toga merupakan tanaman yang tidak membutuhkan lahan yang luas untuk menanam serta dapat memberikan manfaat dalam keluarga sendiri. Manfaat tersebut seperti untuk kebutuhan masak sehari-hari yang kebanyakan berasal dari toga (contoh: kunyit, kencur, jahe) dan untuk tambahan pendapatan keluarga jika diperjualbelikan maupun diolah. Ibu Sisatgas Dwiko Putri kemudian yang mengajak ibu-ibu rumah tangga di sekitarnya yang mau berpartisipasi untuk melakukan penanaman maupun percobaan untuk mengolah toga. Inilah awal terbentuknya kelompok wanita tani dan kemudian Ibu Sisatgas Dwiko Putri yang dijadikan ketua dari kelompok wanita tani tersebut. Pada umumnya, di lahan rumah mitra dijumpai tanaman jahe dan kencur yang melimpah. 


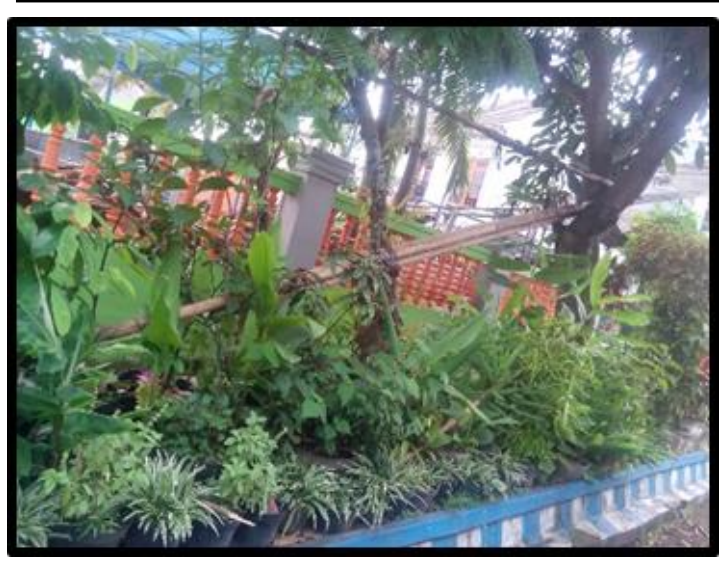

Gambar 1. Tanaman Toga di Wilayah Mitra

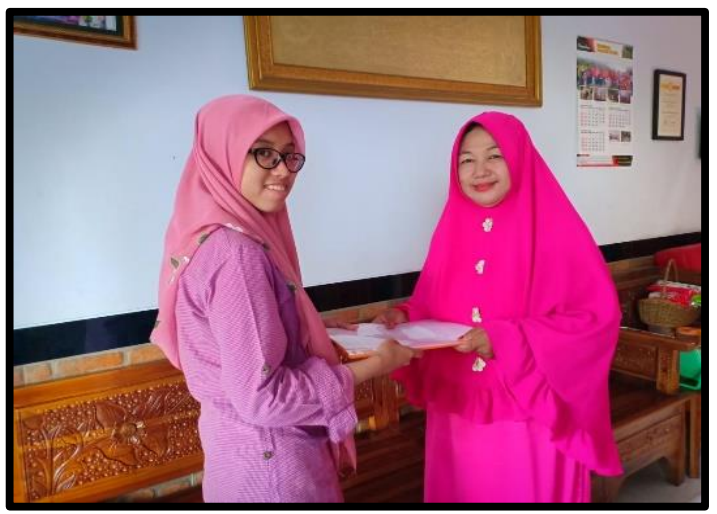

Gambar 2. Mitra Kelompok Wanita Tani

Berbagai usaha dilakukan kelompok wanita tani mitra untuk melakukan percobaan untuk mengolah tanaman obat keluarga pada tahun 2006. Mereka hanya menggunakan percobaan trial and error untuk mendapatkan hasil yang diinginkan. Setelah itu mereka berusaha untuk mendapatkan dana untuk mengembangkan usaha ini melalui kompetisi di berbagai tingkatan dan event usaha. Bahkan berkat kerja keras tersebut kelompok wanita tani ini berhasil memenangkan kompetisi di tingkat nasional. Usaha kelompok tani ini tidak berhenti sampai di sini saja, mereka terus mempromosikan produk yang dimiliki ke berbagai pihak baik sesama rekan usaha maupun di event kewirausahaan, namun ada hal yang belum dioptimalkan yaitu melimpahnya toga di daerah mitra ini.

Hasil wawancara dengan ibu Dwiko, melimpahnya hasil tanam toga ini, masyarakat melakukan proses pembuatan bubuk (simplisia) tanaman jahe, kunyit, maupun kencur. Bubuk olahan ini termasuk famili dari zingiberaceae, hasil olahan ini dijual di koperasi setempat. Usaha ini mengalami kemunduran usaha, karena kurang diminati oleh masyarakat karena masyarakat merasa bosan dengan melimpahnya bubuk tersebut. Kemudian kelompok wanita tani berupaya untuk menjual ke supermarket di wilayah tersebut, namun kalah bersaing dengan olahan bubuk yang sudah mempunyai merk dagang.

Berdasarkan permasalahan ini, perlu untuk melakukan pendampingan kreativitas serta inovasi terhadap bubuk toga ini sebagai bahan baku es krim. Fenomena dekade ini muncul es krim dari berbagai varian, namun belum ada usaha bisnis es krim berbasis tanaman toga terutama famili zingiberaceae.

Ide gagasan ini untuk mencuatkan dan menghilirisasi hasil penelitian tentang zingiberaceae. Penelitian terhadap 
zingiberaceae terhadap fibrinolisis pembuluh darah telah dilakukan. Ekstrak rimpang jahe dan kunyit (Curcuma domestica) dapat bersifat sebagai fibrinolisis darah yang diujikan menggunakan sampel darah segar sapi (Athiroh \& Jumrodah, 2001; Athiroh \& Rosiyanti, 2004; Athiroh \& Wijayanti, 2003). Pada sistem gastrointestinal, jahe dapat digunakan untuk mengobati rasa mual, muntah, dispepsia, spasme abdomen dan ulkus (Khushtar et al., 2009; Pairul et al., 2018). Jahe juga menurunkan asam lambung dan mencegah iritasi pada mukosa lambung (Nanjundaiah et al., 2011; Setyawan, 2015)

Khasiat jahe akan semakin bagus jika dikombinasikan dengan sesama zingiberaceae, misalnya kencur. Kencur memiliki aktivitas sebagai obat asma, anti jamur dan antibakteri (Mohammad \& Elvianto, 2013). Rizoma kencur mengandung monoterpenoids $(29,57 \%)$, sesquiterpenoids $\quad(2,01), \quad$ dan phenylpropanoids $(67,6)$ (Liu et al., 2014). Secara etnobotani kencur digunakan sebagai diare, malnutrisi, rematik, sakit maag, batuk, asma, gangguan saluran pencernaan, demam, ramuan untuk meigkatkan stamina, minuman ibu pasca melahirkan, dan bahan sauna tradisional (Silalahi, 2019; Silalahi et al., 2015). Jahekencur telah terbukti sangat berkhasiat untuk kesehatan, dengan demikian maka perlu dijadikan solusi bagi masyarakat sasaran.

Berdasarkan permasalahan tersebut, dibutuhkan solusi untuk pengembangan usaha yang berasal dari pemberdayaan masyarakat. Inovasi baru dalam pengolahan toga ini sangat diperlukan untuk mengembangkan potensi alam maupun Sumber Daya Manusia (SDM) yang dimiliki oleh masyarakat desa Mangliawan ini. Salah satu inovasi yang akan digunakan yaitu inovasi es krim jahe dan kencur. Inovasi tersebut diharapkan akan mampu meningkatkan komoditas toga desa dan meningkatkan kemampuan masyarakat dalam mengolah tanaman obat keluarga untuk dijadikan produk yang mampu memiliki nilai jual tinggi dan produk khas dari desa Mangliawan.

Es krim jahe - kencur ini merupakan inovasi es krim yang bertujuan sebagai produk olahan makanan yang baik untuk kesehatan. Dengan adanya inovasi es krim ini dapat membantu untuk mengurangi ketergantungan masyarakat terhadap makanan instan yang kurang sehat. Kandungan jahe dan kencur dalam es krim ini dapat menjadi solusi alternatif terhadap makanan instan yang lebih sehat. 


\section{METODE}

1. Pola dan Frekuensi Pelaksanaan Program

Pola dari program terdiri atas persiapan dan pelaksanaan. Persiapan meliputi: a) koordinasi tim dan penyusunan rancangan, b) mapping daerah sasaran, c) ijin pelaksanaan program, d) pemilihan responden. Kegiatan ini bermitra dengan kelompok wanita tani desa Mangliawan sebagai kelompok yang mengembangkan pemanfaatan tanaman obat keluarga dan pemberi rekomendasi terhadap tempat pengembangan usaha pengolahan tanaman obat keluarga. Frekuensi pelaksanaan ke lapangan dilakukan sebanyak dua kali dengan alokasi survey yang pertama untuk melakukan pengamatan secara umum terhadap masyarakat desa Mangliawan dan yang kedua untuk melakukan pemilihan yang akan dijadikan mitra (Basuki, 2006).

Pelaksanaan meliputi: a) sosialisasi program, b) pelatihan pembuatan es krim jahe dan kencur, c) pembentukan kelompok swadaya masyarakat sebagai mitra program, d) monitoring program, e) focus group discussion (FGD), f) evaluasi, g) laporan program, h) seminar dan publikasi. Frekuensi pelaksanannya yaitu sebanyak lima kali menuju lapangan, dengan rincian alokasi kegiatan yaitu kunjungan pertama untuk melakukan sosialisasi program melalui penyampaian materi, kunjungan kedua untuk melakukan sosialisasi lanjutan dan membentuk FGD (Focus Group Discussion), kunjungan ketiga untuk melakukan pelatihan dan membentuk kelompok swadaya masyarakat, kunjungan keempat dan ke lima dialokasikan untuk pemantauan dan evaluasi. Jumlah responden $25 \%$ dari jumlah kelompok mitra.

2. Teknik Pengumpulan, Pengolahan, dan Analisis Data

Teknik pengumpulan data pada kegiatan ini yaitu dengan teknik kuesioner yang bertujuan untuk memperoleh gambaran secara langsung dari masyarakat desa Mangliawan RW. 15 Kota Malang terhadap pemanfaatan tanaman toga utamanya jahe dan kencur. Selain itu juga ada teknik terjun langsung. Tujuan dari terjun langsung yaitu untuk mengetahui jumlah penduduk yang menanam tanaman obat serta memanfaatkan tanaman obat sebagai usaha.

Pengamatan langsung ini tidak dilakukan di semua rumah di desa Mangliawan, namun menggunakan metode sampling purposive dengan berdasarkan responden yang memiliki tanaman obat di rumahnya dan memanfaatkan tanaman obat baik untuk usaha maupun keperluan seharihari. 


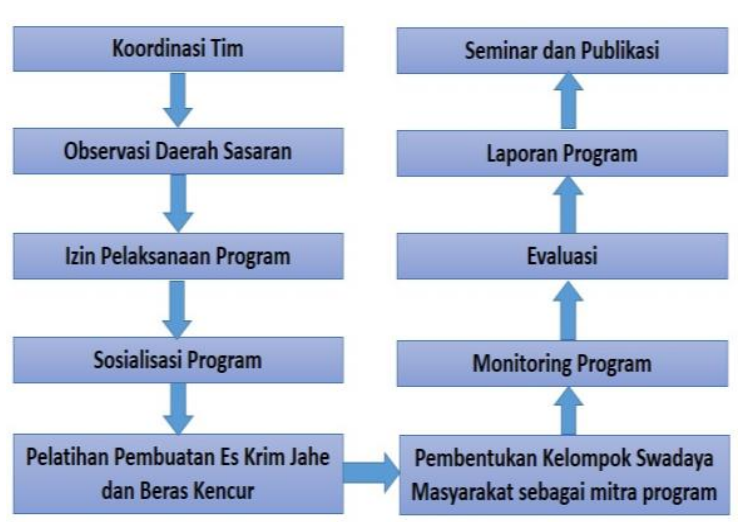

Gambar 3. Alur Tahapan Kegiatan Pengabdian

Rincian tahapan pekerjaan antara lain yaitu sebagai berikut :

1. Koordinasi Tim. Kegiatan koordinasi dengan tim bertujuan untuk mempersiapkan materi dan segala keperluan untuk bersosialisasi dengan pihak desa beserta masyarakat sasaran, guna mengarahkan masyarakat yang sadar akan manfaat dilakukannya budidaya tanaman obat keluarga dan pembuatan es krim jahe dan beras kencur. Pada tahap koordinasi tim ini juga dibuat Standard Operational Procedures (SOP) pendampingan Es krim jahe - kencur untuk memudahkan tahapan setiap langkah pekerjaan, serta pekerjaan yang dilakukan terstruktur dengan baik.

2. Observasi dan mapping daerah sasaran di RW. 15 Dusun Krajan, desa Mangliawan. Bertujuan untuk mengenal lebih jauh kebutuhan masyarakat setempat dan permasalahan yang dihadapi.
Diharapkan dengan dilakukannya program yang direncanakan menjadi tepat guna dan tepat sasaran.

3. Ijin pelaksanaan program. Proses kunjungan daerah sasaran, tahapan selanjutnya adalah permohonan ijin dan kerjasama sebagai mitra program pelatihan pembuatan es krim jahe dan beras kencur di RW. 15 Dusun Krajan barat, desa Mangliawan. Dengan adanya mitra yang berkomitmen mendukung program pengembangan inovasi es krim jahe- kencur, diharapkan program dapat berjalan sesuai rencana.

4. Sosialisasi dilakukan untuk melakukan penyuluhan pada masyarakat agar memanfaatkan tanaman obat keluarga terutama jahe dan kencur. Sosialisasi ini memaparkan bahwa akan diadakan kegiatan pelatihan pembuatan es krim jahe kencur sebagai solusi pengembangan usaha kelompok wanita tani dusun krajan barat. Dalam sosialisasi ini juga diadakan pemberian kuesioner pada masyarakat sebelum dilakukan penyuluhan dan setelahnya untuk mengetahui tingkat pemahaman masyarakat akan pemanfaatan tanaman obat keluarga. Selain itu juga dilakukan Metode Focus Group Discussion (FGD) dalam sosialisasi untuk mengetahui sejauh mana 
kemampuan yang dimiliki masyarakat setempat dalam mengembangkan ide pemanfaatan tanaman obat keluarga.

5. Pelatihan Pembuatan Es krim Jahe Kencur.

Pelatihan Pembuatan es krim dipimpin oleh pemateri yang nantinya mengajarkan langsung kepada masyarakat dalam pembuatan es krim menggunakan alat dan bahan yang telah disediakan. Pelatihan dilaksanakan selama satu hari dan masyarakat diharapkan dapat memanfaatkan pengetahuan yang didapat untuk mengembangkan usaha.

Cara pembuatan es krim jahe dan kencur adalah sebagai berikut: alat dan bahan : mixer, kompor, panci, freezer, sendok makan, mangkok, kotak tupperware, gelas, cup es krim, segelas air (jahe - kencur), $500 \mathrm{ml}$ susu cair, 4 sdm tepung maizena, 8 sdm bubuk krim, $12 \mathrm{sdm}$ gula pasir, $2 \mathrm{sdm}$ SP (pengembang adonan).

Teknik pembuatan es krim jahekencur adalah sebagai berikut : mempersiapkan alat dan bahan, mencampurkan air jahe-kencur, susu, bubuk krim, gula pasir. Adonan dipanaskan hingga mendidih. Selanjutnya melarutkan tepung maizena dengan menambah air secukupnya dan memasukkan larutan ke dalam adonan yang sedang dipanaskan. Ditunggu hingga adonan mengental kemudian ditiriskan. Langkah selanjutnya memasukkan adonan ke dalam freezer selama 1 jam dan setelah 1 jam, adonan ditambah SP yang sudah dipanaskan sebentar dan aduk adonan menggunakan mixer hingga mengembang. Adonan sudah siap untuk dimasukkan cup es krim. Cup es krim yang berisi adonan dimasukkan kembali ke freezer hingga membeku dan Es krim siap saji.

6. Pembentukan Kelompok Swadaya Masyarakat Sebagai Mitra Program. Mitra program yaitu Kelompok Swadaya Masyarakat bertangungjawab terhadap pengembangan yang dalam hal ini terdiri dari kelompok wanita tani dan masyarakat RT.04 Dusun Krajan barat. Kelompok Swadaya Masyarakat yang dibentuk diharapkan mampu mengembangkan inovasi es krim jahe-kencur.

7. Monitoring Program. Kegiatan monitoring dilakukan kepada kader pemantau program. Dimana kegiatan ini dilakukan untuk melihat kinerja para kader program inovasi es krim jahe-kencur di RT.04 dusun Krajan barat, desa Mangliawan.

8. Evaluasi dan Keberlanjutan Program 
9. Evaluasi dilakukan pada akhir program kegiatan tersebut guna mengukur sejauh mana pencapaian dari program tersebut dan hasil akhir program. Hasil akhir ini menjadi bahan evaluasi untuk program selanjutnya.

10. Laporan akhir dibuat untuk laporan pertanggung jawaban program yang telah dilaksanakan.

11. Seminar dan Publikasi. Tahap terakhir adalah seminar dan publikasi yang bertujuan menyebarluaskan hasil kegiatan kepada publik agar bermanfaat dan dengan publikasi ini kami dapat menambah dan memperkaya pengetahuan.

\section{HASIL}

Kegiatan ini dilaksanakan pada bulan Desember sampai Januari 2020 bertempat di rumah Ibu Sisatgas Dwiko Putri, warga dusun Krajan Barat, desa Mangliawan yang berprofesi sebagai ketua kelompok wanita tani. Kegiatan pengabdian kepada masyarakat ini dilakukan dengan cara penyuluhan, pelatihan dan demonstrasi.

Kegiatan dimulai dengan melakukan survei lapangan untuk tahap penyusunan rencana kerja. Kegiatan survei ini dilakukan guna untuk mengidentifikasi permasalahan yang ada di desa Mangliawan yang dapat dicarikan solusinya dengan kegiatan masyarakat. Kegiatan survey tersebut menghasilkan kesepakatan hasil diskusi dengan kepala desa Mangliawan.

Kegiatan penyuluhan dan pelatihan ini mengenai Inovasi Es Krim Kencur-Jahe Haltheco (Halal, Thoyib, Ecofriendly) Sebagai Pengembangan Tani desa Mangliawan Malang dilakukan melalui tahapan sebagai berikut :

\section{Persiapan kegiatan meliputi :}

a) Kegiatan survei tempat pengabdian masyarakat yaitu di dusun Krajan Barat, desa Mangliawan Malang

b) Permohonan ijin kegiatan pengabdian masyarakat kepada pengurus dan Kepala Dusun Krajan Barat, desa Mangliawan Malang

c) Pengurusan administrasi (suratmenyurat)

d) Persiapan alat dan bahan serta akomodasi

e) Persiapan tempat untuk penyuluhan dan pelatihan yaitu menggunakan salah satu tempat tinggal warga dusun tersebut

\section{Kegiatan penyuluhan dan pelatihan} meliputi :

a) Pembukaan dan perkenalan dengan Ibu-Ibu warga dusun Krajan Barat, desa Mangliawan Malang yang menjadi sasaran kegiatan

b) Penyuluhan dan pelatihan mengenai potensi empon-empon, hasil riset 
tentang potensi empon-empon, manfaat empon-empon bagi kesehatan dan pelatihan pembuatan es krim jahe-kencur

c) Pemberian kuesioner saat pra kegiatan dan post kegiatan

d) Sesi diskusi/tanya jawab dengan peserta

\section{Evaluasi dan Keberlanjutan}

\section{Program}

a) Evaluasi dilakukan pada akhir program kegiatan tersebut guna mengukur sejauh mana pencapaian dari program tersebut dan hasil akhir program. Hasil akhir ini menjadi bahan evaluasi untuk program selanjutnya

b) Laporan program dibuat untuk laporan pertanggung jawaban program yang telah dilaksanakan

c) Seminar dan publikasi

d) Tahap terakhir adalah seminar dan publikasi yang bertujuan menyebarluaskan hasil kegiatan kepada publik agar bermanfaat dan dengan publikasi ini kami dapat menambah dan memperkaya pengetahuan.

\section{Demografi Responden}

Responden merupakan Ibu-ibu kelompok wanita tani yang ditentukan berdasarkan perwakilan dari setiap RT yang aktif di desa Mangliawan. Data dalam pengabdian diperoleh melalui kuesioner kepada 12 responden. Mayoritas responden berusia 49-72 tahun dengan mayoritas pekerjaan adalah sebagai Ibu Rumah Tangga dan sebagian kecil sebagai wirausaha, guru, pensiunan dan asesor UKM.

\section{Tingkat Pengetahuan Masyarakat mengenai potensi jahe-kencur dan olahannya}

$$
\text { Informasi mengenai tingkat }
$$
pengetahuan masyarakat mengenai potensi jahe-kencur dan produk olahannya diperoleh melalui kuesioner yang berisi pertanyaan-pertanyaan. Kuesioner dilakukan saat pra kegiatan dan post kegiatan.

\section{PEMBAHASAN}

Potensi tanaman jahe dan kencur di desa Mangliawan cukup melimpah, hal ini berdasarkan hasil kuesoner yang diperoleh. Warga desa Mangliawan mayoritas mengolah jahe kencur dalam bentuk minuman seduhan. Warga sangat antusias sekali ketika kegiatan penyuluhan/pelatihan ini dilaksanakan. Hal ini dibuktikan hasil kuesioner sebelum kegiatan dan setelah kegiatan pada Tabel 1. 
Tabel 1. Hasil Rekapitulasi Pengetahuan Masyarakat Mengenai Potensi Jahe-Kencur dan Olahannya

\begin{tabular}{|c|c|c|c|c|c|c|c|}
\hline \multirow{2}{*}{ No } & \multirow{2}{*}{ Skala penilaian } & \multicolumn{3}{|c|}{$\begin{array}{c}\text { Sebelum } \\
\text { penyuluhan/pelatihan } \\
\end{array}$} & \multicolumn{3}{|c|}{$\begin{array}{c}\text { Sesudah } \\
\text { penyuluhan/pelatihan } \\
\end{array}$} \\
\hline & & Tahu & $\begin{array}{l}\text { Cukup } \\
\text { tahu }\end{array}$ & $\begin{array}{l}\text { Tidak } \\
\text { tahu }\end{array}$ & Tahu & $\begin{array}{l}\text { Cukup } \\
\text { tahu }\end{array}$ & $\begin{array}{l}\text { Tidak } \\
\text { tahu }\end{array}$ \\
\hline \multicolumn{8}{|c|}{ Pengetahuan tentang: } \\
\hline 1 & Pembuatan es krim jahe-kencur & 0 & 0 & 12 & 12 & 0 & 0 \\
\hline 2 & Manfaat es krim jahe-kencur & 7 & 2 & 3 & 12 & 0 & 0 \\
\hline 3 & $\begin{array}{l}\text { Rencana membuka usaha es krim } \\
\text { jahe-kencur }\end{array}$ & 7 & 3 & 2 & 10 & 1 & 1 \\
\hline
\end{tabular}

Sumber: Data Primer, 2020 (diolah)

Tujuan dari kegiatan adalah mengembangkan potensi jehe-kencur melalui pembuatan eskrim jahe kencur maka diharapkan produk ini menjadi produk unggulan kelompok wanita tani desa mangliawan yang bersifat komersial.

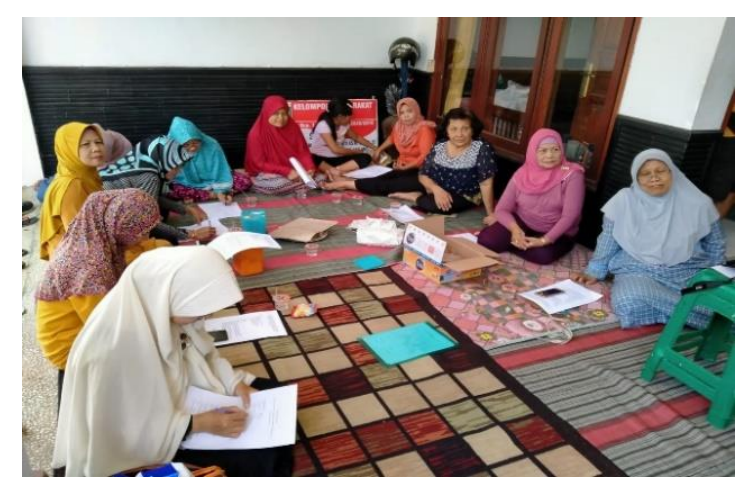

Gambar 4. Antusias Kelompok Sasaran Saat Pengisian Kuesioener Pasca Pelatihan Inovasi Es Krim Jahe-Kencur

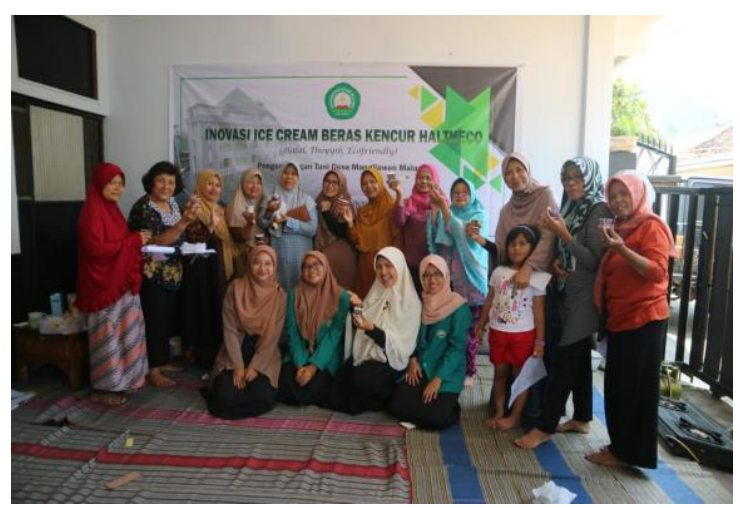

Gambar 5. Masyarakat Sasaran dengan Produk Es Krim Jahe-Kencur
Terjadi peningkatan $100 \%$ responden terhadap pemahaman pengetahuan pembuatan es krim jahe kencur. Pengetahuan masyarakat terhadap manfaat es krim jahe- kencur terjadi peningkatan pengetahuan $75 \%$. Upaya keinginan responden membuka rencana usaha es krim jahe - kencur sebesar $83.3 \%$.

Berdasarkan hasil kuesioner yang diperoleh, produk es krim jahe kencur mayoritas dapat diterima oleh masyarakat berdasarkan uji inderawi dan kesukaan. Parameter pertama yang di uji adalah tekstur yang merupakan kenampakan luar suatu produk yang dapat diamati secara langsung. Tekstur pada produk akan mempengaruhi penilaian tentang diterima atau tidaknya produk tersebut.

Parameter kedua adalah warna yang merupakan aspek pertama yang langsung diamati oleh panelis karena warna merupakan kenampakan yang langsung dilihat oleh indera penglihatan. Data penilaian kualitas warna eskrim $66,66 \%$ cukup suka dengan warnanya. Hal ini 
p-ISSN : 2548-8783

e-ISSN : 2548-8791

dikarenakan warna asli dari jahe dan kencur dominan krem, namun tidak mengurangi kemanfaatan dari es krim.

Selanjutnya produk bahan pangan tidak hanya terdiri dari satu rasa, tetapi merupakan gabungan berbagai macam rasa secara terpadu sehingga menimbulkan cita rasa yang utuh. Indikator rasa yang dinilai dalam penelitian ini adalah rasa manis. Maka diperlukan inovasi yang menggabungkan jahe dan kencur. Warga suka akan rasanya sebanyak 91,66\%. tentunya akan menambah selera jika ada topping di atas es krimnya. Inovasi es krim berbahan toga atau herbal perlu dikembangkan dikomersilkan, karena pada umumnya masyarakat sangat menyukai es krim.

Hasil kuesioner mengenai uji indrawi ditampilkan pada Tabel 2. 
Tabel 2. Hasil Rekapitulasi Uji Inderawi dan Kesukaan Produk Es Krim Jahe - Kencur

\begin{tabular}{clcccccc}
\hline \multirow{2}{*}{ No } & \multirow{2}{*}{ Skala penilaian } & \multicolumn{3}{c}{ Suka } & \multicolumn{2}{c}{ Cukup suka } & \multicolumn{2}{c}{ Tidak suka } \\
\cline { 3 - 8 } & & $\mathbf{n}$ & $\mathbf{\%}$ & $\mathbf{n}$ & $\mathbf{\%}$ & $\mathbf{n}$ & $\mathbf{\%}$ \\
\hline 1 & Tekstur & 12 & 100 & 0 & 0 & 0 & 0 \\
\hline 2 & Rasa & 11 & 91,66 & 1 & 8,33 & 0 & 0 \\
\hline 3 & Warna & 4 & 33,33 & 8 & 66,66 & 0 & 0 \\
\hline 4 & Rasa original & 9 & 75 & 2 & 16,66 & 1 & 8,33 \\
\hline 5 & Penambahan topping & 10 & 83,33 & 1 & 8,33 & 1 & 8,33 \\
\hline
\end{tabular}

Sumber: Data Primer, 2020 (diolah)

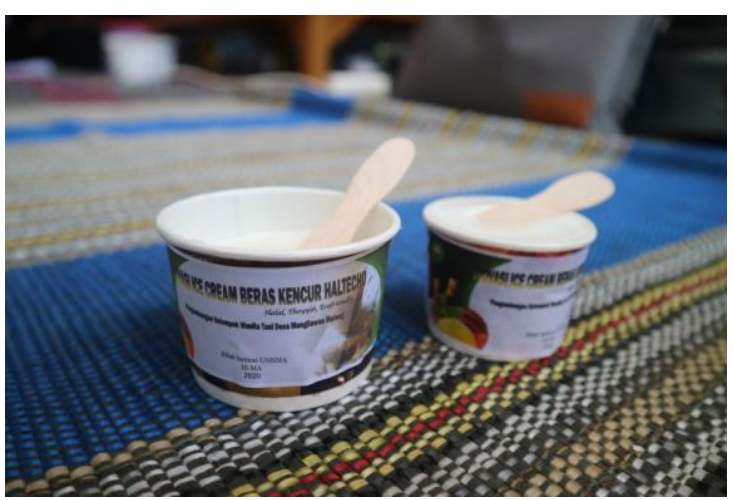

Gambar 6. Produk Es Krim Jahe-Kencur

Hasil pengabdian ini selaras dengan hasil pengabdian tentang Pelatihan Pembuatan Es Krim Buah Naga Sebagai Upaya Peningkatan Gizi Keluarga bagi Kader PKK Kadipiro Banjarsari Surakarta. Hasil pengabdiannya yaitu 1) peserta memiliki pemahaman tentang nutrisi buah naga; 2) masyarakat memahami prosedur membuat es krim buah naga buatan sendiri; 3) masyarakat dapat membuat es krim sendiri (Harjanti et al., 2020).

\section{SIMPULAN}

Pengetahuan masyarakat terhadap potensi jahe kencur dan olahannya mengalami peningkatan. Terjadi peningkatan $100 \%$ responden terhadap pemahaman pegetahuan pembuatan es krim jahe kencur. Pengetahuan masyarakat terhadap manfaat es krim jahe- kencur terjadi peningkatan pengetahuan $75 \%$. Upaya keinginan responden membuka rencana usaha es krim jahe - kencur sebesar $83.3 \%$. Warga suka akan rasanya sebanyak $91,66 \%$. tentunya akan menambah selera jika ada topping diatas es krimnya. Masyarakat meyakini jahe kencur merupakan bahan alami, bebas dari bahan kimia, murah, dan khasiatnya lebih terasa. Semua kalangan masyarakat menyukai es krim jahe kencur baik anak-anak sampai dengan orang tua. Konsep pengelolaan dan pelestarian tumbuhan obat adalah dengan meningkatkan pemanfaatannya untuk dapat memberikan kesejahteraan bagi masyarakat dalam aspek pengobatan dan juga meningkatkan perekonomian penduduk desa.

\section{SARAN}

Perlu adanya kegiatan lanjutan tentang uji laboratorium dan analisis kelayakan usaha sehingga bisa meningkatkan perekonomian masyarakat. 


\section{UCAPAN TERIMA KASIH}

Ketua dan ang?s'fn,;g/'sD'd

WeDdh.d.

agota pengabdi mengucapkan terimakasih kepada Universitas Islam Malang (UNISMA) Malang atas bantuan dana Hibah Institusi UNISMA (HI-ma) tahun 2019. Terimakasih pula disampaikan untuk kelompok wanita tani desa Mangliawan serta tim mahasiswa yang ikut berpartisipasi dalam program pengabdian kepada masyarakat.

\section{DAFTAR PUSTAKA}

Andriati, A., \& Wahjudi, R. M. T. (2016). Tingkat penerimaan penggunaan jamu sebagai alternatif penggunaan obat modern pada masyarakat ekonomi rendah-menengah dan atas. Masyarakat, Kebudayaan dan Politik, 29(3), 133-145. https://doi.org/10.20473/mkp.V29I 32016.133-145

Athiroh, N., \& Jumrodah. (2001). Uji Potensi Ekstrak Rimpang Kunyit (Curcuma domestica Val.) terhadap Anti Koagulasi pada Darah. Fakultas MIPA, Universitas Islam Malang.

Athiroh, N., \& Rosiyanti. (2004). Uji Potensi Ekstrak Rimpang Jahe (Zingiber officinale Roxb) sebagai
Fibrinolisis Darah. Fakultas MIPA, Universitas Islam Malang

Athiroh, N., \& Wijayanti, E. (2003). Uji Potensi Rimpang Kunyit Putih (Curcuma zedoaria) dan Rimpang Kunyit (Curcuma domestica) Sebagai Fibrinolisis Terhadap Darah. Fakultas MIPA, Universitas Islam Malang

Basuki, S. (2006). Metode Penelitian Kualitatif. Jakarta: WedatamaWidya Sastra.

Harjanti, R., Aisiyah, S., Nopiyanti, V., Sunarni, T., \& Suhartinah, S. (2020). Pelatihan Pembuatan Es Krim Buah Naga Sebagai Upaya Peningkatan Gizi Keluarga bagi Kader PKK Kadipiro Banjarsari Surakarta. Journal of Dedicators Community, 4(1), 41-46.

Khushtar, M., Kumar, V., Javed, K., \& Bhandari, U. (2009). Protective effect of ginger oil on aspirin and pylorus ligation-induced gastric ulcer model in rats. Indian Journal of Pharmaceutical Sciences, 71(5), 554.

Liu, X. C., Liang, Y., Shi, W. P., Liu, Q. Z., Zhou, L., \& Liu, Z. L. (2014). Repellent and insecticidal effects of the essential oil of Kaempferia galanga rhizomes to Liposcelis bostrychophila (Psocoptera: 
Liposcelidae). Journal of Economic

Entomology, 107(4), 1706-1712.

Mohammad, I. H., \& Elvianto, D. D.

(2013). Minyak Kencur Dari

Rimpang Kencur dengan Variabel

Jumlah Pelarut dan Waktu

Maserasi. Jurnal Teknik Kimia, $8(1)$.

Nanjundaiah, S. M., Annaiah, H. N. M., \&

Dharmesh, S. M. (2011).

Gastroprotective Effect of Ginger

Rhizome (Zingiber officinale)

Extract: Role of Gallic Acid and

Cinnamic Acid in H, K-ATPase/H.

pylori Inhibition and Anti-oxidative Mechanism.

Pairul, P. P. B., Susianti, S., \& Nasution, S.

H. (2018). Jahe (Zingiber Officinale) Sebagai Anti

Ulserogenik. Jurnal Medula, 7(5), $42-46$.

Setyawan, B. (2015). Peluang Usaha Budidaya Jahe. Penerbit Pustaka Baru Press Yogakarta, Indonesia.

Silalahi, M. (2019). An ethnobotanical study of traditional steam-bathing by the Batak people of North Sumatra, Indonesia. Pacific Conservation Biology, 25(3), 266282.

Silalahi, M., Walujo, E. B., Supriatna, J., \& Mangunwardoyo, W. (2015). The local knowledge of medicinal plants trader and diversity of medicinal plants in the Kabanjahe traditional market, North Sumatra, Indonesia. Journal of Ethnopharmacology, $175,432-443$.

Winarti, C., \& Nurdjanah, N. (2005). Peluang tanaman rempah dan obat sebagai sumber pangan fungsional. Jurnal Litbang Pertanian, 24(2), 47-55. 